\title{
EFFECT OF ALLOYING ELEMENTS ON PLASTIC WORKABILITY AND CORROSION BEHAVIOR OF Ti-X (X = 6 Co, 8 Cr, 4 Fe, 6 Mn, 10 Mo, AND 36 Nb) BINARY ALLOYS
}

\begin{abstract}
The purpose of this study was to investigate the effect of the alloying elements on the plastic workability and corrosion behavior of Ti-X (wt.\%) $(\mathrm{X}=6 \mathrm{Co}, 8 \mathrm{Cr}, 4 \mathrm{Fe}, 6 \mathrm{Mn}, 10 \mathrm{Mo}$, and $36 \mathrm{Nb})$ binary alloys. The alloys with a molybdenum equivalence of $10 \mathrm{wt} . \%$ were fabricated by a vacuum arc re-melting process and were then homogenized at a temperature $20^{\circ} \mathrm{C}$ greater than the beta transus temperature for $14.4 \mathrm{ks}$. The plastic workability was investigated under uniaxial cold rolling, while the corrosion behavior was examined in Ringer's solution at $37^{\circ} \mathrm{C}$. Among the Ti-X alloys, the Ti- 8 wt.\% $\mathrm{Cr}$ and Ti- 6 wt. $\%$ Mn alloys showed an outstanding plastic workability and corrosion resistance, respectively.
\end{abstract}

Keywords: molybdenum equivalence, titanium binary alloys, plastic workability, corrosion behavior, potentiodynamic

\section{Introduction}

Titanium alloys are widely used for biomedical applications because of their high strength, low elastic modulus, excellent corrosion resistance, and superior biocompatibility [1]. Ti-6Al$4 \mathrm{~V}$ is one of the titanium alloys registered as an implant material in the ASTM standards. However, the exposure of such alloys to vanadium and aluminum, may cause senile dementia, neurological disorders, or allergic reactions in humans [3]. Thus, the current research is mainly focused on vanadium- and aluminumfree beta type titanium alloys as their elastic modulus is similar to that of the human bone (20 GPa) [4].

Many titanium alloys composed of beta phase stabilizers including $\mathrm{Mo}, \mathrm{Cr}, \mathrm{Nb}, \mathrm{Mn}, \mathrm{Co}$, and $\mathrm{Fe}$ have been studied for biomedical applications. Mo and $\mathrm{Nb}$ are excellent beta phase stabilizers that decrease the elastic moduli of titanium alloys [5]. Ti-Cr alloys have high tensile strength and good ductility for dental applications [6]. Furthermore, Ti-Mn alloys exhibit a high ultimate tensile strength, low elastic modulus ( $94 \mathrm{GPa}$ ), and good biocompatibility [7]. R. Wang and G. Welsch have reported that Ti-Co alloys exhibit an improved cast quality and a high tensile strength [8]. Fe has been widely used as an alloying element in titanium alloys for biomedical applications because of its high strength and low elastic modulus [9].

The beta phase stability of titanium alloys can be described by means of the molybdenum equivalence $\left(\mathrm{Mo}_{\mathrm{eq}}\right)$, which is calculated from the composition of titanium alloys [10]. For instance, Ti-4Al-5Mo-5V-6Cr (wt.\%) showed an increased strength and a decreased fracture toughness as the $\mathrm{Mo}_{\mathrm{eq}}$ increased. It has been reported that the $\mathrm{Mo}_{\mathrm{eq}}$ values lying in the range of 12-15 wt.\% yield an optimal combination of the strength and toughness [11]. The formation of the stress induced $\alpha^{\prime \prime}$ phase in alloys with $\mathrm{Mo}_{\mathrm{eq}}$ less than $10 \mathrm{wt} . \%$ results in grain refinement [12].

In this study, titanium binary alloys with a $\mathrm{Mo}_{\mathrm{eq}}$ of $10 \mathrm{wt} . \%$ were prepared by the amount of beta phase stabilizers, including $\mathrm{Cr}, \mathrm{Mn}, \mathrm{Fe}, \mathrm{Co}, \mathrm{Nb}$, and Mo. Their microstructural evolution, hardness, and corrosion properties in Ringer's solution were investigated after uniaxial cold rolling.

\section{Experimental}

The alloy design was based on the $\mathrm{Mo}_{\mathrm{eq}}$ according to Eq. (1) $[10]$ :

$$
\begin{aligned}
& \mathrm{Mo}_{\mathrm{eq}}(\mathrm{wt} . \%)=[\mathrm{Mo}]+0.2[\mathrm{Ta}]+0.67[\mathrm{~V}]+ \\
& +1.25[\mathrm{Cr}]+0.44[\mathrm{~W}]+0.28[\mathrm{Nb}]+1.25[\mathrm{Ni}]+ \\
& +1.7[\mathrm{Mn}]+1.7[\mathrm{Co}]+2.5[\mathrm{Fe}]-[\mathrm{Al}](\mathrm{wt} . \%)
\end{aligned}
$$

The ingots of the Ti-X (wt.\%) (X=6 Co, $8 \mathrm{Cr}, 4 \mathrm{Fe}, 6 \mathrm{Mn}$, $10 \mathrm{Mo}$, and $36 \mathrm{Nb}$ ) binary alloys were fabricated by a vacuum arc remelting (VAR, ACE VACUUM, AVA-1500, Korea) process. Commercially pure titanium chips (ASTM CP Grade II), Mo bars (99.8 wt.\%), V sheets (99.9 wt.\%), Cr chips (99.9 wt.\%), Sn balls (99.9 wt.\%), and Zr sheets (99.9 wt.\%) were arc melted in a water-cooled copper hearth with a tungsten electrode. The compositions of the titanium binary alloys are shown in Table 1 . The ingots were remelted three times under an argon atmosphere to ensure chemical homogeneity. The ingots of the Ti-X alloys were then homogenized at a temperature $20^{\circ} \mathrm{C}$ greater than the

\footnotetext{
* SCHOOL OF MATERIALS SCIENCE AND ENGINEERING, CHONNAM NATIONAL UNIVERSITY, GWANGJU 61186, REPUBLIC OF KOREA

\# Corresponding author: kmlee@jnu.ac.kr
} 
1186

beta transus temperature for $14.4 \mathrm{ks}$ followed by a furnace cooling. The uniaxial cold rolling (TAE HENG PRECISION, TH500, Korea) was performed on the Ti-X binary alloys to evaluate their cold plastic workability. The hardness was measured by a Rockwell hardness testing machine (HEUNGJIN, HJ-8362, Korea) to investigate the changes after cold rolling.

The microstructures of the alloys were observed with an optical microscope (OM, Leaci Microsystems Ltd., CH-9435, Germany). The samples were etched for a duration of 8-10 $\mathrm{s}$ in a solution of $1 \mathrm{~L}$ distilled water, $10 \mathrm{ml} \mathrm{HF}$, and $15 \mathrm{ml} \mathrm{HNO}_{3}$. All the samples were wet ground with waterproof silicon carbide papers to 2000 grit and were polished with a colloidal silica suspension followed by an ultrasonic cleaning. The phase constitutions of the alloys were examined by X-ray diffraction (XRD, PANalytical, X' Pert pro, Netherland) analysis using $\mathrm{Cu}-\mathrm{K} \alpha$ radiation with a $2 \theta$ range of $30-80^{\circ}$ at an accelerating
TABLE 1

Composition of titanium binary alloys with an $\mathrm{Mo}_{\mathrm{eq}}$ of $10 \mathrm{wt} . \%$ and the beta transus temperature of each alloy

\begin{tabular}{|c|c|c|}
\hline \hline Alloy composition (wt.\%) & $\mathbf{M o}_{\mathbf{e q}}$ (wt.\%) & $\mathbf{T}_{\boldsymbol{\beta} \text { tr }}\left({ }^{\circ} \mathbf{C}\right)$ \\
\hline $\mathrm{Ti}-8 \mathrm{Cr}$ & 10 & 730 \\
\hline $\mathrm{Ti}-6 \mathrm{Mn}$ & 10 & 760 \\
\hline $\mathrm{Ti}-4 \mathrm{Fe}$ & 10 & 820 \\
\hline $\mathrm{Ti}-6 \mathrm{Co}$ & 10 & 760 \\
\hline $\mathrm{Ti}-36 \mathrm{Nb}$ & 10 & 530 \\
\hline $\mathrm{Ti}-10 \mathrm{Mo}$ & 10 & 780 \\
\hline
\end{tabular}

voltage of $40 \mathrm{kV}$, a current of $250 \mathrm{~mA}$, and a scanning speed of $2 \% \mathrm{~min}$.

The electrochemical experiments were conducted in a standard three-electrode cell corrosion tester (PARSTAT 2273, Princeton Applied Research, USA) at $37^{\circ} \mathrm{C}$, which included
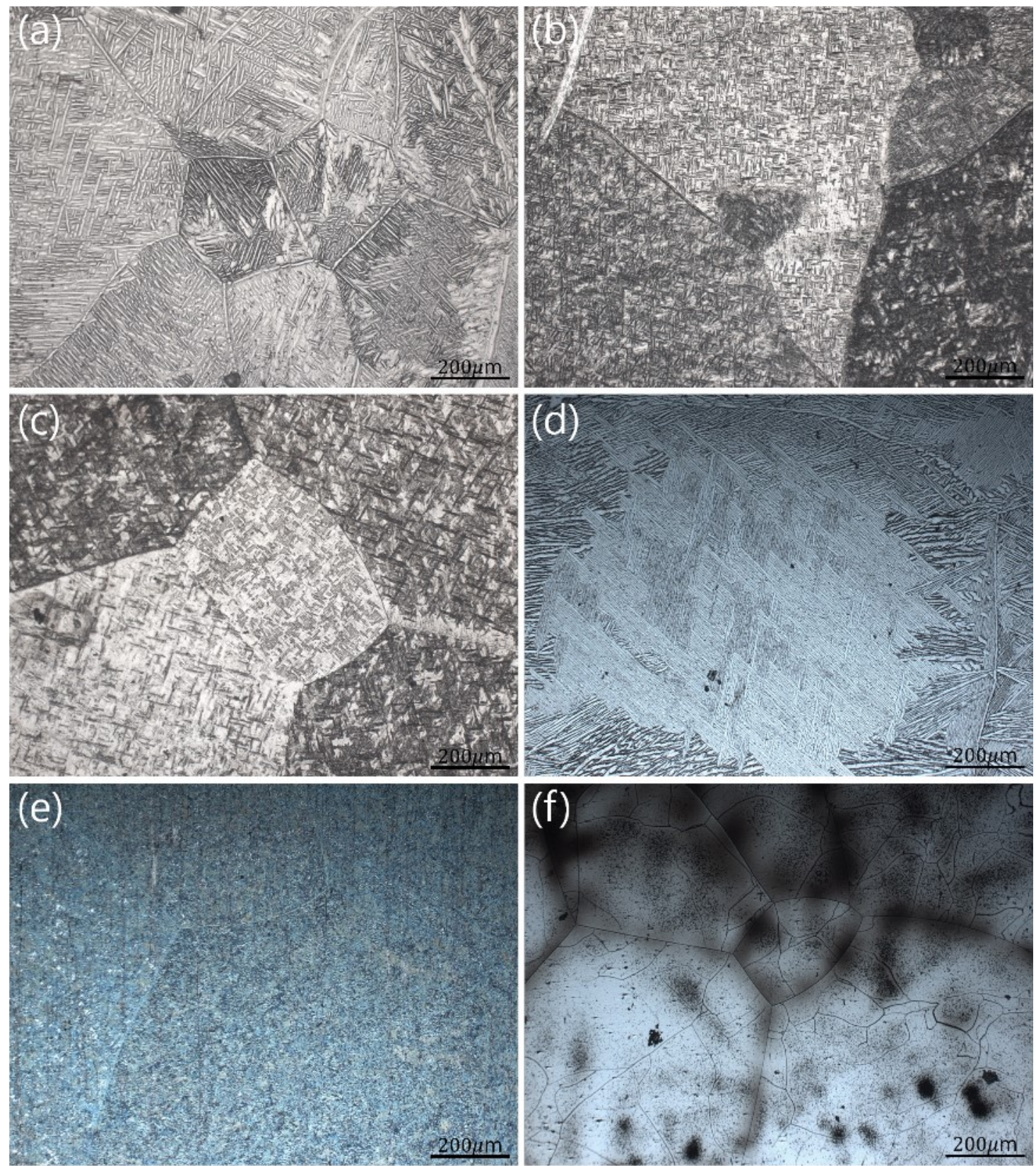

Fig. 1. Optical micrographs of the homogenized Ti-X alloys (wt.\%): (a) Ti-4Fe, (b) Ti-6Mn, (c) Ti-8Cr, (d) Ti-6Co, (e) Ti-10Mo, and (f) Ti-36Nb 
a working electrode with an exposed area of $1 \mathrm{~cm}^{2}$, a platinum mesh as a counter electrode, and a silver/silver chloride reference electrode. The working electrolyte was a naturally aerated aqueous Ringer's physiological solution $\left(\mathrm{NaCl}=9.00 \mathrm{~g} \mathrm{~L}^{-1}\right.$; $\left.\mathrm{CaCl}_{2}=0.24 \mathrm{~g} \mathrm{~L}^{-1} ; \mathrm{KCl}=0.43 \mathrm{~g} \mathrm{~L}^{-1} ; \mathrm{NaHCO}_{3}=0.2 \mathrm{~g} \mathrm{~L}^{-1}\right)$.

\section{Results and discussion}

Table 2 gives the thickness reduction of the titanium alloys after uniaxial cold rolling without the formation of any cracks. The Ti- 8 wt.\% Cr alloy showed a relatively higher thickness reduction than the other alloys. Such an availability of $\mathrm{Cr}$ to the workability of titanium has also been reported by $\mathrm{Ho}$ et al. [6]. The Ti-6 wt.\% Mn and Ti-10 wt.\% Mo alloys also showed a fairly good cold plastic workability.
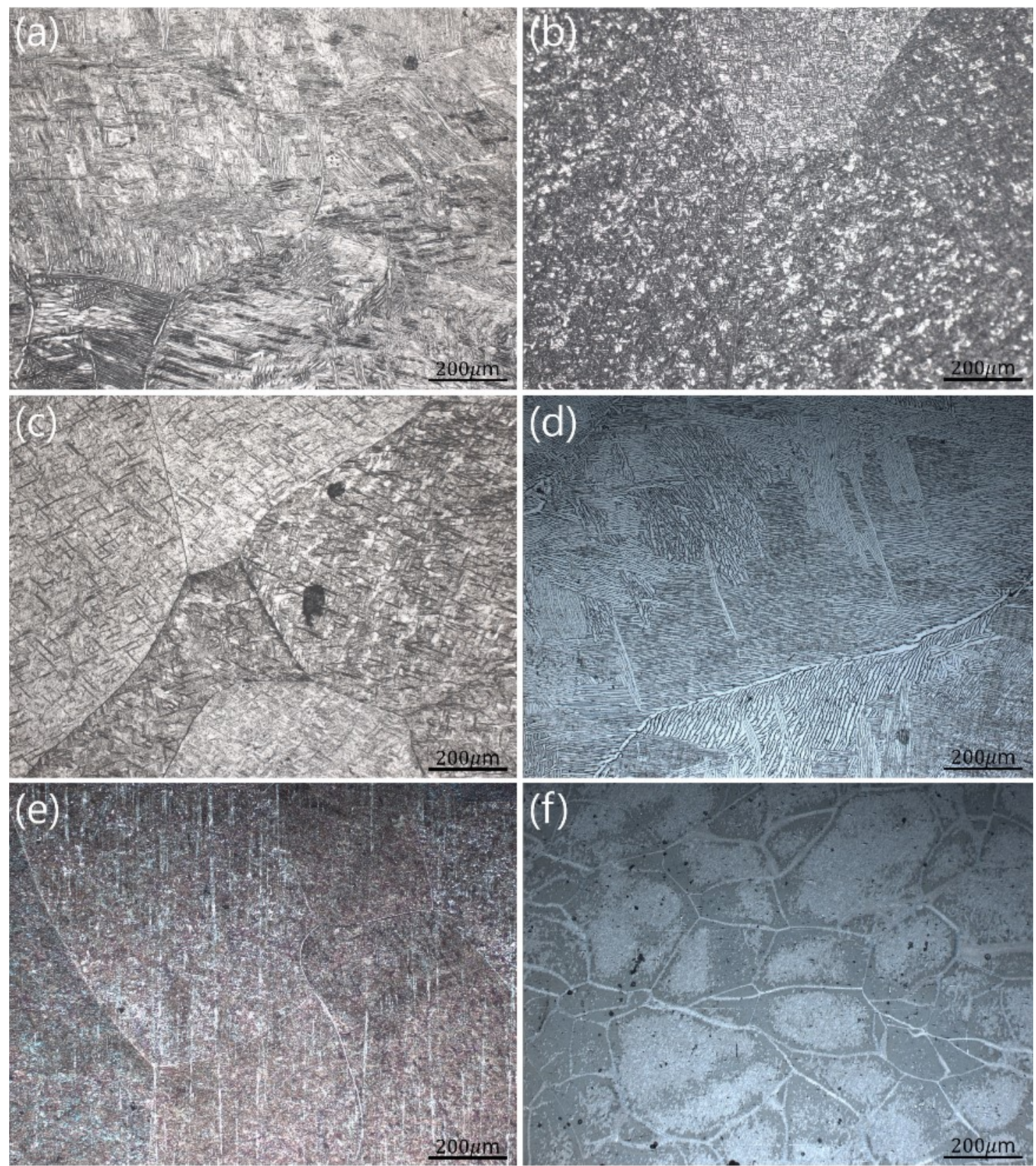

Fig. 2. Optical micrographs of the cold-rolled Ti-X alloys (wt.\%): (a) Ti-4Fe, (b) Ti-6Mn, (c) Ti-8Cr, (d) Ti-6Co, (e) Ti-10Mo, and (f) Ti-36Nb 
wt.\% Fe, and Ti-6 wt.\% Co alloys exhibited a typical Widmanstätten structure of the $\alpha$ phase, as can be seen from Fig. 1a-e. The size of the acicular structures of the Ti- 8 wt.\% Cr, Ti-6 wt.\% Mn, and Ti-10 wt.\% Mo alloys was smaller than that of the lamellae structures observed in the case of the Ti- 4 wt. $\% \mathrm{Fe}$ and Ti- 6 wt.\% Co alloys. The workability of the Ti- 8 wt.\% Cr, Ti-6 wt. $\%$ Mn, and Ti-10 wt.\% Mo alloys was superior to that of the Ti-4 wt.\% Fe and Ti- 6 wt.\% Co alloys, which indicates that the acicular microstructure observed in titanium alloys resulted in better cold workability than the lamellar microstructure. As shown in Table 2, the thickness reduction in Ti-36 wt.\% $\mathrm{Nb}$ was extremely small as compared to that in the other alloys. $\mathrm{Nb}$ is commonly used as an alloying element for Ti alloys because of its significant biocompatibility, superplasticity, and shape memory effect. However, the mechanical properties of Ti alloys can be deteriorated when the amount of $\mathrm{Nb}$ is more than 25 at\%. Kim et al. reported that Ti-(28-29) at $\% \mathrm{Nb}$ alloys exhibit neither a shape memory effect nor a superplastic behavior [13].

Figure 3 shows the XRD patterns of the homogenized and cold-rolled Ti-X binary alloys. The $\alpha$ phase intensity of the
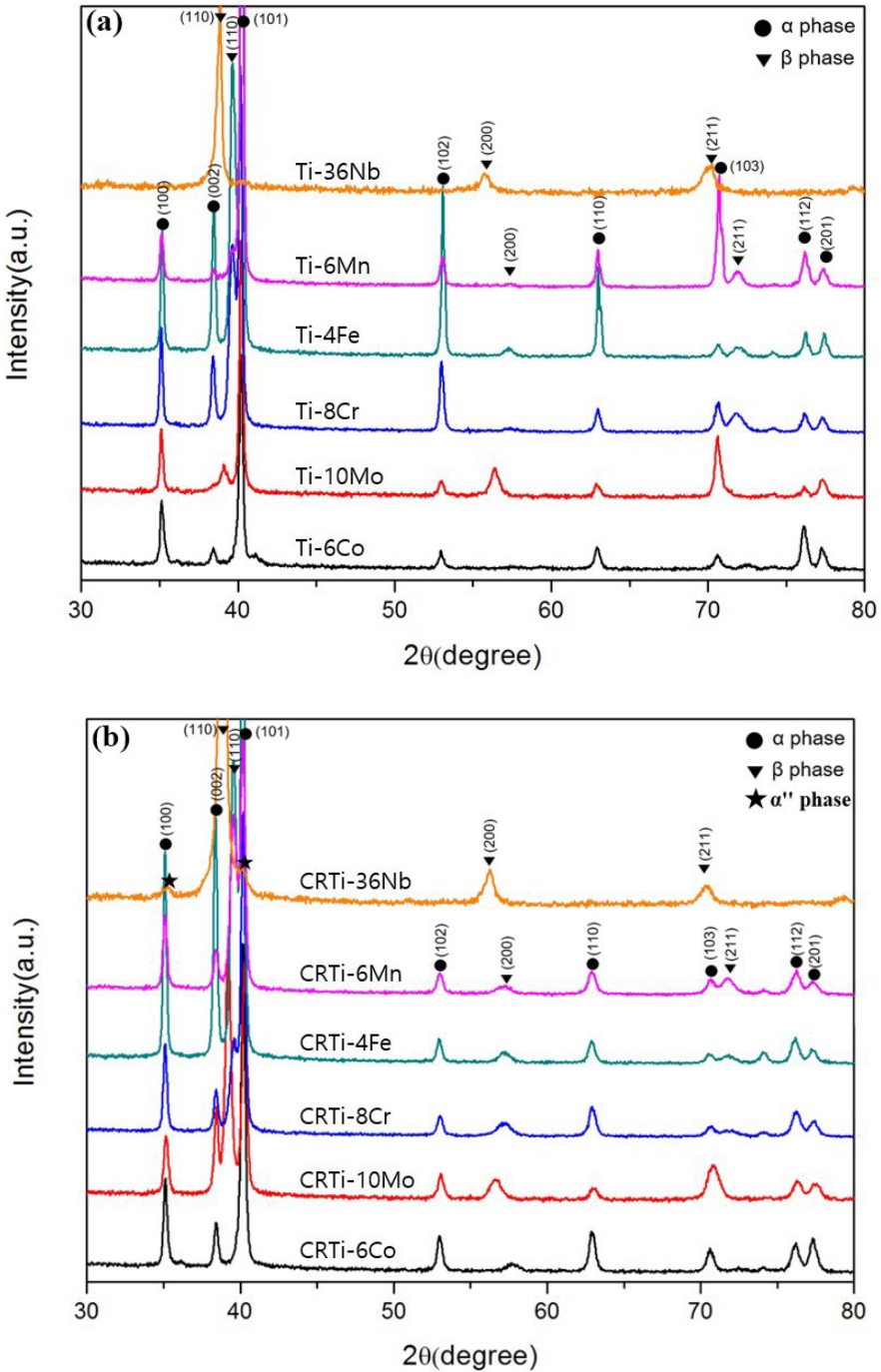

Fig. 3. XRD patterns of the Ti-X (wt.\%) (X=6 Co, $10 \mathrm{Mo}, 8 \mathrm{Cr}, 4 \mathrm{Fe}$, $6 \mathrm{Mn}$, and $36 \mathrm{Nb}$ ) binary alloys subjected to (a) homogenization and (b) cold rolling
(101) plane was extremely high in the homogenized Ti-8 wt.\% Cr, Ti-6 wt.\% Mn, Ti-10 wt.\% Mo, Ti-4 wt.\% Fe, and Ti-6 wt.\% Co alloys, indicating that the $\alpha$ phase was the dominant phase in these alloys. This is attributed to the slow cooling rate in the furnace. The XRD patterns of the cold-rolled alloys showed no significant changes and the intensity of the (101) $\alpha$ remained high even after the cold rolling. The microstructures of the alloys (both cold-rolled and homogenized) were also similar. However, the homogenized Ti-36 wt.\% Nb alloy showed a single beta phase, while the cold-rolled Ti-36 wt.\% Nb alloy exhibited stress induced martensitic $\alpha^{\prime \prime}$ phases. The Ti-36 wt.\% Nb alloy showed a better beta phase stability than the other alloys even though the $\mathrm{Mo}_{\mathrm{eq}}$ values were the same for all the alloys.

Figure 4 shows the Rockwell hardness of the homogenized and cold-rolled Ti-X binary alloys. The hardness of all the alloys increased after cold rolling as a result of the dense distribution of the $\alpha$ phase followed by a slight decrease in the grain sizes after cold rolling. Such an increase in the hardness of the Ti-36 wt.\% $\mathrm{Nb}$ alloy after cold rolling was attributed to the precipitation of stress induced martensitic $\alpha^{\prime \prime}$ phases at the grain boundaries and in the grains. The homogenized Ti-10 wt.\% Mo alloy exhibited a relatively higher hardness than the other homogenized alloys. This suggests that molybdenum significantly improves the strength of titanium binary alloys. Similar result was reported by Min et al. [14].

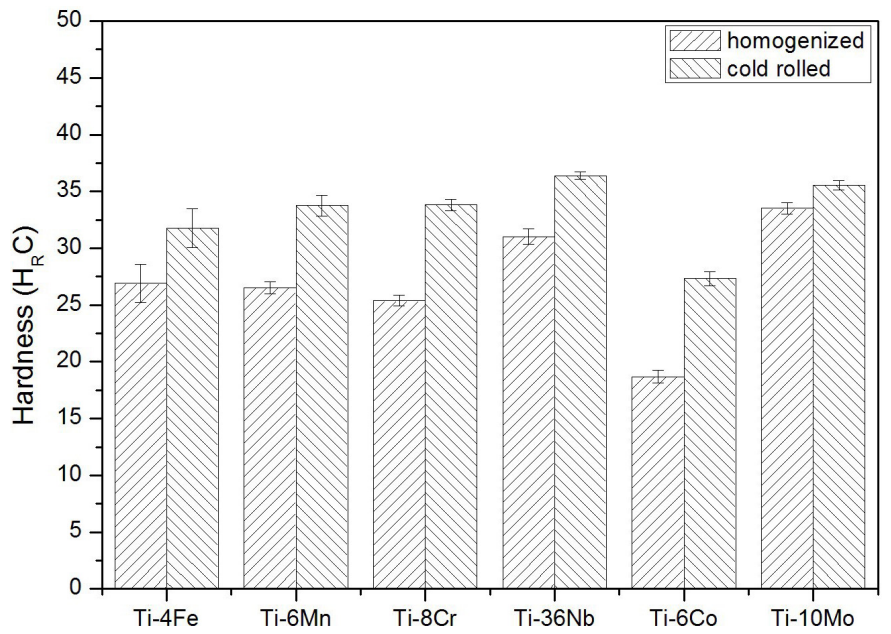

Fig. 4. Rockwell hardness of the Ti-X (wt.\%) (X $=6 \mathrm{Co}, 8 \mathrm{Cr}, 4 \mathrm{Fe}$, $6 \mathrm{Mn}, 10 \mathrm{Mo}$, and $36 \mathrm{Nb}$ ) binary alloys subjected to homogenization and cold rolling

Table 3 shows the corrosion parameters of the potentiodynamic polarization curves in Ringer's solution at $37^{\circ} \mathrm{C}$ derived from Fig. 5. Both the corrosion and passive current densities of the alloys clearly decreased after cold rolling, while the corrosion potentials increased with the exception of the Ti-10 wt.\% Mo alloy. The corrosion properties of the titanium binary alloys improved after cold rolling. This is attributed to the high dislocation density and reduced grain size caused by the cold rolling process. High grain boundary volumes improve the passivation kinetics, which leads to a rapid formation of a protective pas- 
Corrosion parameters of potentiodynamic polarization for the homogenized and cold-rolled titanium binary alloys in Ringer's solution at $37^{\circ} \mathrm{C}$

\begin{tabular}{|c|c|c|c|c|c|c|}
\hline \hline \multirow{2}{*}{$\begin{array}{c}\text { Alloy composition } \\
(\mathbf{w t .} \%)\end{array}$} & \multicolumn{3}{|c|}{ Homogenized } & \multicolumn{3}{c|}{ Cold-rolled } \\
\cline { 2 - 7 } & $\boldsymbol{E}_{\text {corr }}\left(\mathbf{V}_{\text {SSC }}\right)$ & $\boldsymbol{i}_{\text {corr }}\left(\mathbf{n A} / \mathbf{c m}^{\mathbf{2}}\right)$ & $\boldsymbol{i}_{\text {pass }}\left(\boldsymbol{\mu A} \mathbf{A} \mathbf{c m}^{\mathbf{2}}\right)$ & $\boldsymbol{E}_{\text {corr }}\left(\mathbf{V}_{\text {SSC }}\right)$ & $\boldsymbol{i}_{\text {corr }}\left(\mathbf{n A} / \mathbf{c m}^{\mathbf{2}}\right)$ & $\boldsymbol{i}_{\text {pass }}\left(\boldsymbol{\mu A} / \mathbf{c m}^{\mathbf{2}}\right)$ \\
\hline $\mathrm{Ti}-8 \mathrm{Cr}$ & -0.318 & 15.28 & 15.55 & -0.253 & 5.958 & 7.145 \\
\hline $\mathrm{Ti}-6 \mathrm{Mn}$ & -0.327 & 7.742 & 14.86 & -0.288 & 5.656 & 8.536 \\
\hline $\mathrm{Ti}-4 \mathrm{Fe}$ & -0.326 & 28.06 & 16.79 & -0.226 & 8.901 & 8.158 \\
\hline $\mathrm{Ti}-6 \mathrm{Co}$ & -0.245 & 21.31 & 15.18 & -0.111 & 13.94 & 9.746 \\
\hline $\mathrm{Ti}-36 \mathrm{Nb}$ & -0.273 & 27.32 & 16.27 & -0.234 & 26.51 & 10.861 \\
\hline $\mathrm{Ti}-10 \mathrm{Mo}$ & -0.214 & 48.81 & 13.11 & -0.235 & 9.283 & 6.548 \\
\hline
\end{tabular}

sive film on the alloy surface [15]. The values of the corrosion current density were found to be of the order of $10^{-8}$ and $10^{-9}$ $\mathrm{A} / \mathrm{cm}^{2}$, which are lower than the reported corrosion current densities of titanium alloys (of the order of $10^{-7} \mathrm{~A} / \mathrm{cm}^{2}$ ) [16]. However, the passive current densities of the cold-rolled alloys (6.548-10.861 $\left.\mu \mathrm{A} / \mathrm{cm}^{2}\right)$ were comparatively higher than those
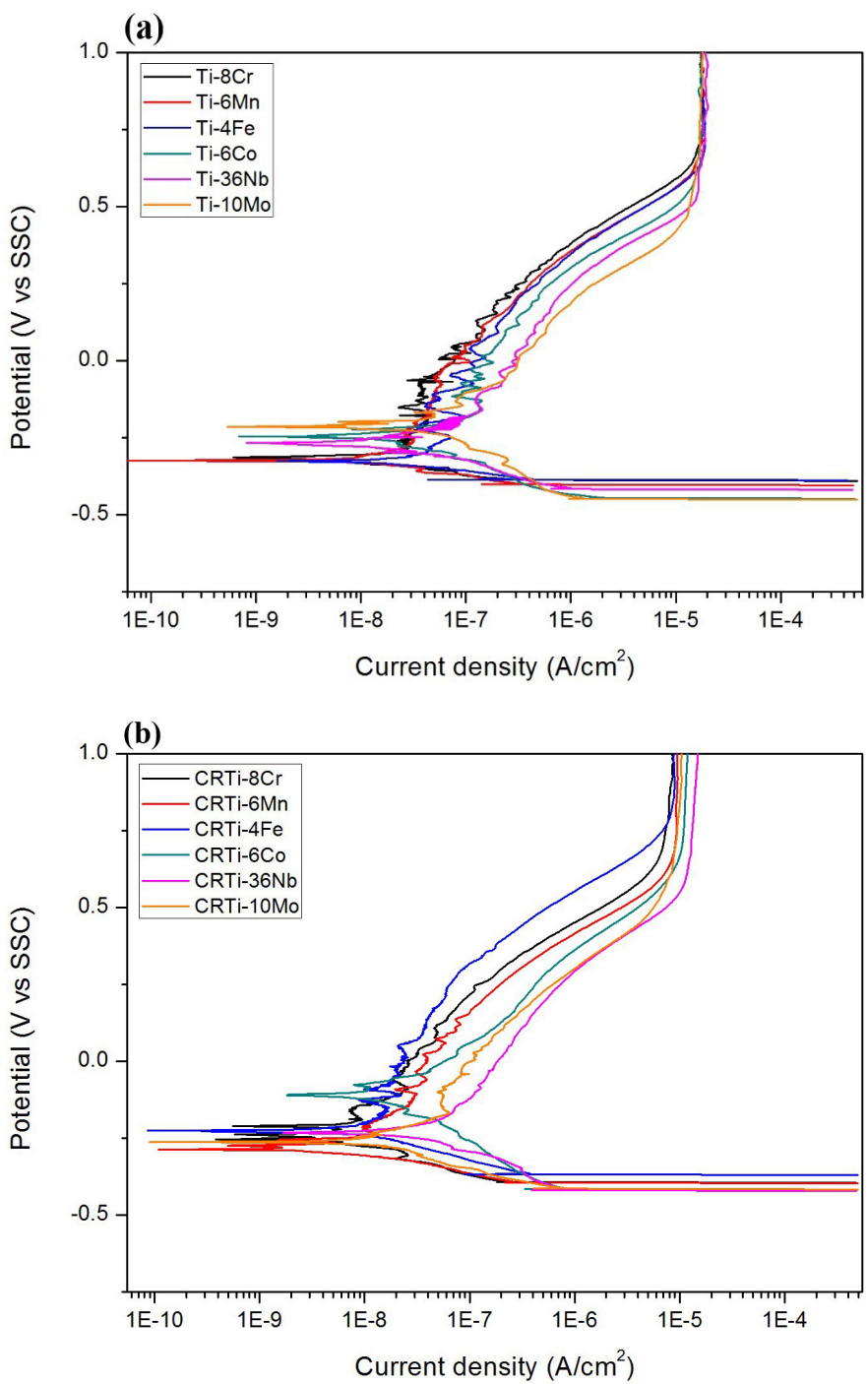

Fig. 5. Polarization curves of the Ti-X (wt.\%) $(\mathrm{X}=6 \mathrm{Co}, 8 \mathrm{Cr}, 4 \mathrm{Fe}, 6$ $\mathrm{Mn}, 10 \mathrm{Mo}$, and $36 \mathrm{Nb}$ ) binary alloys subjected to (a) homogenization and (b) cold rolling reported by Robin et al. $\left(1.01-4.08 \mu \mathrm{A} / \mathrm{cm}^{2}\right)$ [16]. Generally, the passive current density determines the stability of the passive film. High values of passive current densities indicate the poor stability of passive films. Cremasco et al. proposed that high values of passive current density indicate the porous passive $\mathrm{Ti}$ oxide film [17]. The Ti-6 wt.\% Mn alloy showed an excellent corrosion resistance after both the homogenization and cold rolling when compared to the other alloys. The Ti-5 wt.\% Mn alloy shows a superior corrosion resistance with a corrosion current density of $0.572 \mu \mathrm{A} / \mathrm{cm}^{2}$ [18]. The Ti-8 wt. $\% \mathrm{Cr}$ and Ti-10 wt.\% Mo alloys also showed a remarkable corrosion resistance after cold rolling. Both the cold-rolled and solution heat-treated Ti-10 wt.\% Mo alloys exhibited good corrosion behavior, which was attributed to the formation of a passive film of $\mathrm{TiO}_{2}$ and $\mathrm{MoO}_{3}$ [5]. The Ti-5, 10, 15, and $20 \mathrm{wt} . \% \mathrm{Cr}$ alloys showed an improved corrosion resistance in a fluoride-containing saline solution because of the formation of a chromium oxide-rich surface film [19].

\section{Conclusions}

The cold plastic workability and corrosion properties of the Ti-X binary alloys with an $\mathrm{Mo}_{\mathrm{eq}}$ of $10 \mathrm{wt} . \%$ were investigated in this study. The $\alpha$-phases with a Widmanstätten structure were observed in both the homogenized and cold-rolled alloys with the exception of the Ti-36 wt.\% Nb alloy. The Ti- 8 wt.\% Cr alloy exhibited an excellent cold plastic workability with a thickness reduction of $50.6 \%$ after the uniaxial cold rolling. The Ti-10 wt.\% Mo alloy showed the highest hardness value among all the homogenized alloys. The corrosion resistance was enhanced after cold rolling. The Ti- 6 wt.\% Mn alloy showed a better corrosion resistance than the other alloys. Thus, $\mathrm{Cr}, \mathrm{Mn}$, and $\mathrm{Mo}$ are favorable alloying elements for improving the cold plastic workability and corrosion resistance of titanium alloys.

\section{Acknowledgments}

This research was supported by the Basic Science Research Program of the National Research Foundation of Korea (NRF) funded by the Ministry of Education (No. 2015R1D1A1A01056861). 
1190

\section{REFERENCES}

[1] J. Zhang, F. Sun, Y. Hao, N. Gozdecki, E. Lebrun, P. Vermaut, R. Portier, T. Gloriant, P. Laheurte, F. Prima, Mater. Sci. Eng. A 563, 78-85 (2013).

[3] L.J. Xu, Y.Y. Chen, Z.G. Liu, F.T. Kong, Journal of Alloys and Compounds 453, 320-324 (2008).

[4] Y. Zhentao, Z. Lian, Mater. Sci. Eng. A 438-440, 391-394 (2006).

[5] Y.-L. Zhou, D.-M. Luo, Journal of Alloys and Compounds 509, 6267-6272 (2011).

[6] W.-F. Ho, T.-Y. Chiang, S.-C. Wu, H.-C. Hsu, J. Alloy. Compd. 468, 533-538 (2009).

[7] P.F. Santos, M. Niinomi, K. Cho, M. Nakai, H. Liu, N. Ohtsu, M. Hirano, M. Ikeda, T. Narushima, Acta Biomater. 26, 366-376 (2015).

[8] R. Wang, G. Welsch, J. Biomed. Mater. Res. B Appl. Biomater 101, 1419-1427 (2013).

[9] J. Lu, Y. Zhao, H. Niu, Y. Zhang, Y. Du, W. Zhang, W. Huo, Mater. Sci. Eng. C Mater. Biol. Appl. 62, 36-44 (2016).
[10] A. Zafari, X.S. Wei, W. Xu, K. Xia, Acta Mater. 97, 146-155 (2015).

[11] Y.L. Yang, W.Q. Wang, F.L. Li, W.Q. Li, Y.Q. Zhang, Mater. Sci. Forum 618-619, 169-172 (2009).

[12] D. Doraiswamy, S. Ankem, Acta Mater. 51, 1607-1619 (2003).

[13] H.Y. Kim, Y. Ikehara, J.I. Kim, H. Hosoda, S. Miyazaki, Acta Mater. 54, 2419-2429 (2006).

[14] X.H. Min, S. Emura, T. Nishimura, L. Zhang, S. Tamilselvi, K. Tsuchiya, K. Tsuzaki, Mater. Sci. Eng. A 527, 1480-1488 (2010).

[15] H.S. Kim, S.J. Yoo, J.W. Ahn, D.H. Kim, W.J. Kim, Mater. Sci. Eng. A 528, 8479-8485 (2011).

[16] A. Robin, O.A.S. Carvalho, S.G. Schneider, S. Schneider, Mater. Corros. 59, 929-933 (2008).

[17] A. Cremasco, W.R. Osório, C.M.A. Freire, A. Garcia, R. Caram, Electrochim. Acta 53, 4867-4874 (2008).

[18] J.-W. Kim, M.-J. Hwang, M.-K. Han, Y.-G. Kim, H.-J. Song, Y.-J. Park, Mater. Chem. Phys. 180, 341-348 (2016).

[19] S. Takemoto, M. Hattori, M. Yoshinari, E. Kawada, K. Asami, Y. Oda, Dent. Mater. 25, 467-472 (2009). 